\title{
Characterisation of Artocarpus heterophyllus Fibre Reinforced Composite
}

\author{
Tian Hao Chua and Hoo Tien Nicholas Kuan* \\ Department of Mechanical and Manufacturing Engineering, Faculty of Engineering, \\ Universiti Malaysia Sarawak, Kota Samarahan, Sarawak, Malaysia \\ *Email: khtnicholas@unimas.my
}

\begin{abstract}
Natural fibre reinforced polymer composite (NFRPC) has successfully replaced other synthetic fibre for applications in automobile, sport equipment, furniture, electrical appliances, etc. Artocarpus heterophyllus or jackfruit are mass produced in most South East Asia, but most of the parts other than the fruit would go to waste. In this study, Artocarpus heterophyllus fibre reinforced high density polyethylene (HDPE) composite was fabricated and tested for its mechanical properties, such as tensile and hardness properties. Artocarpus heterophyllus fibres were made into sheets using traditional paper making process, before being laminated with HDPE films using hot press method. Different volume fraction of fibre laminates were produced: $10 \%, 13 \%, 17 \%$ and $21 \%$. The study shows that composite with $10 \%, 13 \%$ and $17 \%$ fibre volume fraction exhibits better tensile strength and hardness value than neat HDPE, while composites with 13\%, $17 \%$ and $21 \%$ fibre volume fraction exhibit higher tensile modulus than neat HDPE. The optimum fibre content for the Artocarpus heterophyllus composite is $17 \%$.
\end{abstract}

Keywords: NFRPC, Artocarpus heterophyllus, HDPE, natural fibre

\section{Introduction}

The increasing environmental concern and new regulations are forcing many researchers and industries to seek more eco-friendly approach for material used in their products. One that is gaining increasing popularity is biodegradable polymers. The increasing waste of commodity plastics around the world posed an immediate threat that challenges the sustainability of environment. It is wise to plan a waste management that can recycle those plastic repeatedly and make new products. Many studies have been done to improve the properties of natural fibre reinforced polymer, including studies on chemical adhesion. This is to counter the disadvantage of poor compatibility between fibre and matrix and the relative high moisture absorption. Among the studies on NFRPC also include the effect of fibre loading on tensile properties. It was found that the tensile strength of NFRPC increase with fibre content, up to an optimum level. Its Young's Modulus on the other hand increases with increasing fibre content [1].

Plastics is the second largest municipal solid waste in Malaysia (24\%), second only to organic waste (45\%) [2]. Artocarpus heterophyllus commonly known as jackfruit, is a large spiky fruit known locally for its distinctive tropical sweet flavour. The production of the fruit reached 28,767.2 metric tonnes in Malaysia, which estimated to be valued at RM55 million [3]. The fruits are mostly eaten or made into desserts and snacks. The leftover pulps are left as waste, with little reusable function and

* Corresponding author. Tel.: +6-082-583290; fax: +6-082-583410

E-mail address: khtnicholas@unimas.my

Manuscript History:

Received 12 September, 2018, Revised 27 September, 2018, Accepted 28 September, 2018, Published 30 September, 2018

ISSN: 2289-7771

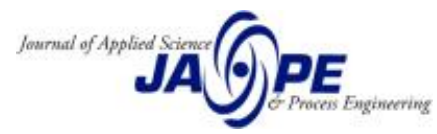


value. Therefore, this study is done, using HDPE as matrix and Artocarpus heterophyllus as fibre reinforcement, in hope of mitigating the problem of plastic waste and make full use of Artocarpus heterophyllus pulp fibres.

In this research, the tensile and hardness properties of Artocarpus heterophyllus fibre reinforced HDPE composites will be studied. Results will be compared with neat HDPE to rectify the function of added fibre.

\section{Methodology}

\subsection{Preparation of Composites}

The composite fabrication Artocarpus heterophyllus (AH) fibre sheets as reinforcing fibres and bio-degradable high-density polyethylene (HDPE) as the matrices. The fruit's peels were obtained from local fruit vendor. The peels were dried in the oven to remove moisture and was stored in a desiccator. The HDPE were supplied from local plastic manufacturer with a density of $0.96 \mathrm{~g} / \mathrm{mL}$ at $23^{\circ} \mathrm{C}$, in the form of sheets with a thickness of $22 \mu \mathrm{m}$. Table 1 shows the composition of Artocarpus heterophyllus (AH) reinforced composites.

Table 1. Composition of Artocarpus heterophyllus (AH) reinforced composites

\begin{tabular}{c|c|c|c}
\hline Laminate & $\begin{array}{c}\text { Fibre Volume } \\
\text { Fraction, } \nu_{\mathrm{f}}(\%)\end{array}$ & $\begin{array}{c}\text { Matrix volume } \\
\text { fraction, } v_{\mathrm{m}}(\%)\end{array}$ & Composition (AH/HDPE) \\
\hline $\mathrm{A}_{0}$ & 0 & 100 & $0 / 100 \mathrm{AH} / \mathrm{HDPE}$ \\
\hline $\mathrm{A}_{1}$ & 10 & 90 & $10 / 90 \mathrm{AH} / \mathrm{HDPE}$ \\
\hline $\mathrm{A}_{2}$ & 13 & 87 & $13 / 87 \mathrm{AH} / \mathrm{HDPE}$ \\
\hline $\mathrm{A}_{3}$ & 17 & 83 & $17 / 83 \mathrm{AH} / \mathrm{HDPE}$ \\
\hline $\mathrm{A}_{4}$ & 21 & 79 & $21 / 79 \mathrm{AH} / \mathrm{HDPE}$ \\
\hline
\end{tabular}

Fibre sheets are made from Artocarpus heterophyllus fibres with the following steps. Firstly, AH's peels are boiled for one hour and left to cool. The peels are then mixed with equal amount of water and are blended using blender for 3 minutes. Pulps undergone screening and sieving consistently over the sieve. After that, the pulps are transferred to wetted canvas, where it will be compressed into sheets under weights. The sheets are dried under the sun. AH papers are cut to $250 \mathrm{~mm} \times 250 \mathrm{~mm}$.

The fibre sheets are laminated with HDPE film and hot-pressed at $180^{\circ} \mathrm{C}$ to form Artocarpus heterophysllus fibres reinforced HDPE composite. Five samples, each with a dimension of $150 \mathrm{~mm} \times$ $25 \mathrm{~mm}$ are cut from every laminate composite.

\subsection{Tensile Test}

The tensile test was carried out using the Shimadzu universal testing machine Model AG-300kN IS MS with compliance to the ASTM D3039 standard. Equation 3.1 and 3.2 are used to calculate the stress and strain of the samples;

$$
\text { Stress, } \sigma=\frac{\text { force applied }(N)}{\text { cross sectional area }\left(\mathrm{mm}^{2}\right)}
$$




$$
\text { Strain, } \varepsilon=\frac{\text { change of length }(\mathrm{mm})}{\text { initial length }(\mathrm{mm})}
$$

\subsection{Hardness Test}

Hardness test is performed using Shimadzu HMV-G21D Micro Vickers Hardness Tester. Test load of $1.961 \mathrm{~N}$ is used and the specimens are viewed under $10 \times$ magnification. The results are in the unit of HV (Vickers hardness).

$$
H V=\frac{\text { Force applied, } F}{\text { Area of indentation, } A}
$$

\subsection{Scanning Electron Microscopy (SEM)}

Scanning electron microscopy (SEM) analysis is used to study the surface morphology of $\mathrm{A}_{1}$ (10/90 AH/HDPE) and $\mathrm{A}_{4}$ (21/79 AH/HDPE) composite. Hitachi TM3030 Tabletop Microscope is used for SEM analysis.

\section{Result \& Discussion}

\subsection{Specific Tensile Strength}

Figure 1 shows the average specific tensile strength of AH fibre composite. The optimum percentage for specific tensile strength is at $17 \%$ fibre volume fraction, which yield a 0.0184 $\mathrm{MPa} \cdot \mathrm{m}^{3} / \mathrm{kg}$. With $21 \%$ fibre volume fraction, the specific tensile strength is the lowest, which is 0.0158 $\mathrm{MPa} \cdot \mathrm{m}^{3} / \mathrm{kg}$, where neat PE laminate exhibit a specific tensile strength of $0.0169 \mathrm{MPa} \cdot \mathrm{m}^{3} / \mathrm{kg}$. The optimum AH fibre to reinforce HDPE is with $17 \%$ fibre volume fraction, too much fibre will cause weak adhesion between the hydrophilic fibre and hydrophobic matrix to became poor and deteriorate in tensile properties. Heat treatment increases the crystallinity index of the fibre, thereby increase the fibre's strength [4]. In short, AH fibre reinforced HDPE composites is low in density but exhibit a higher tensile strength. 


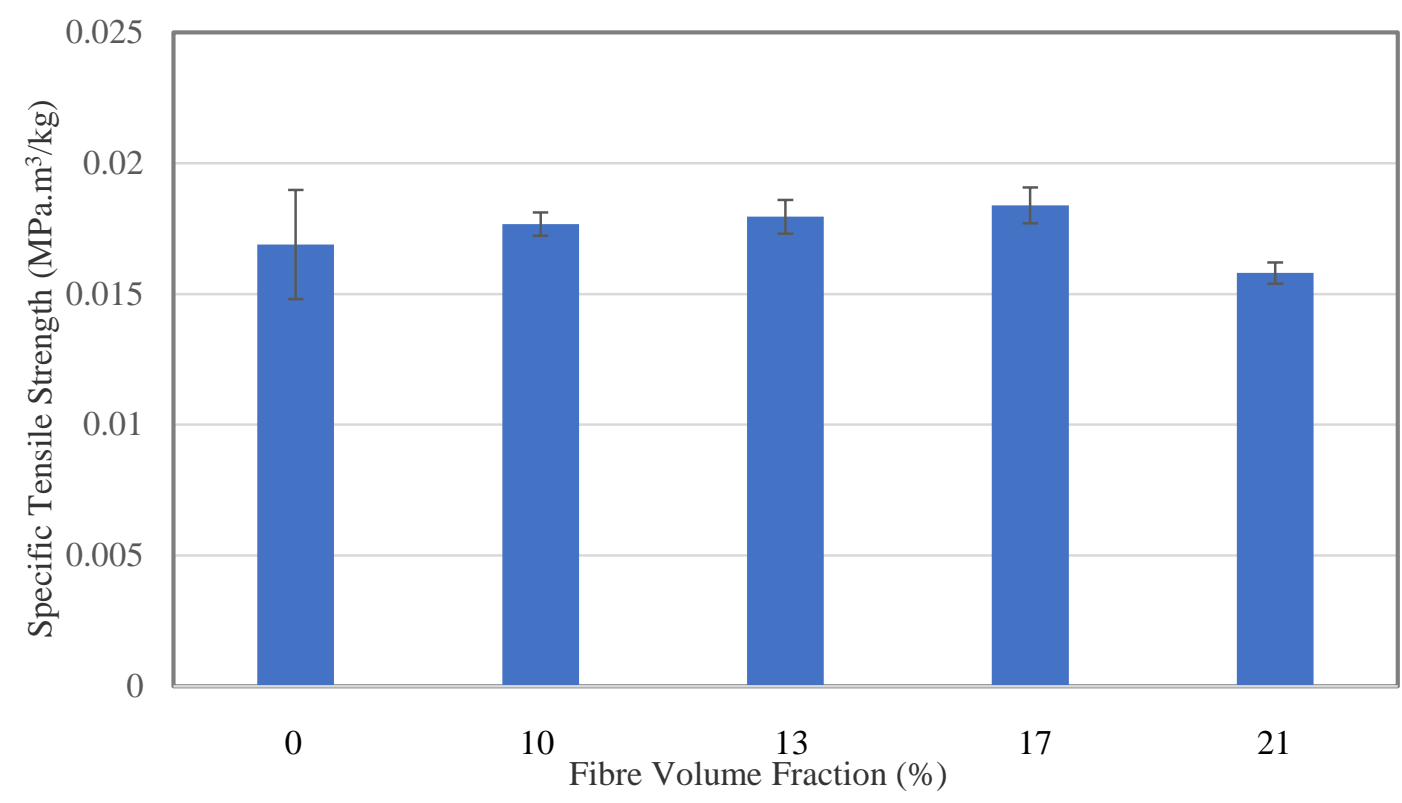

Figure 1. Average specific tensile strength of AH fibre composites.

\subsection{Specific Tensile Modulus}

Figure 2 compares the specific tensile modulus of AH fibre composite. The maximum specific tensile modulus is $0.58 \mathrm{MPa} \cdot \mathrm{m}^{3} / \mathrm{kg}$ at $17 \%$ fibre volume fraction, while the $0 \%$ and $10 \%$ laminates have similar specific tensile modulus of 0.476 and $0.471 \mathrm{MPa} \cdot \mathrm{m}^{3} / \mathrm{kg}$. AH fibre composite have lower density but higher tensile modulus than neat HDPE.

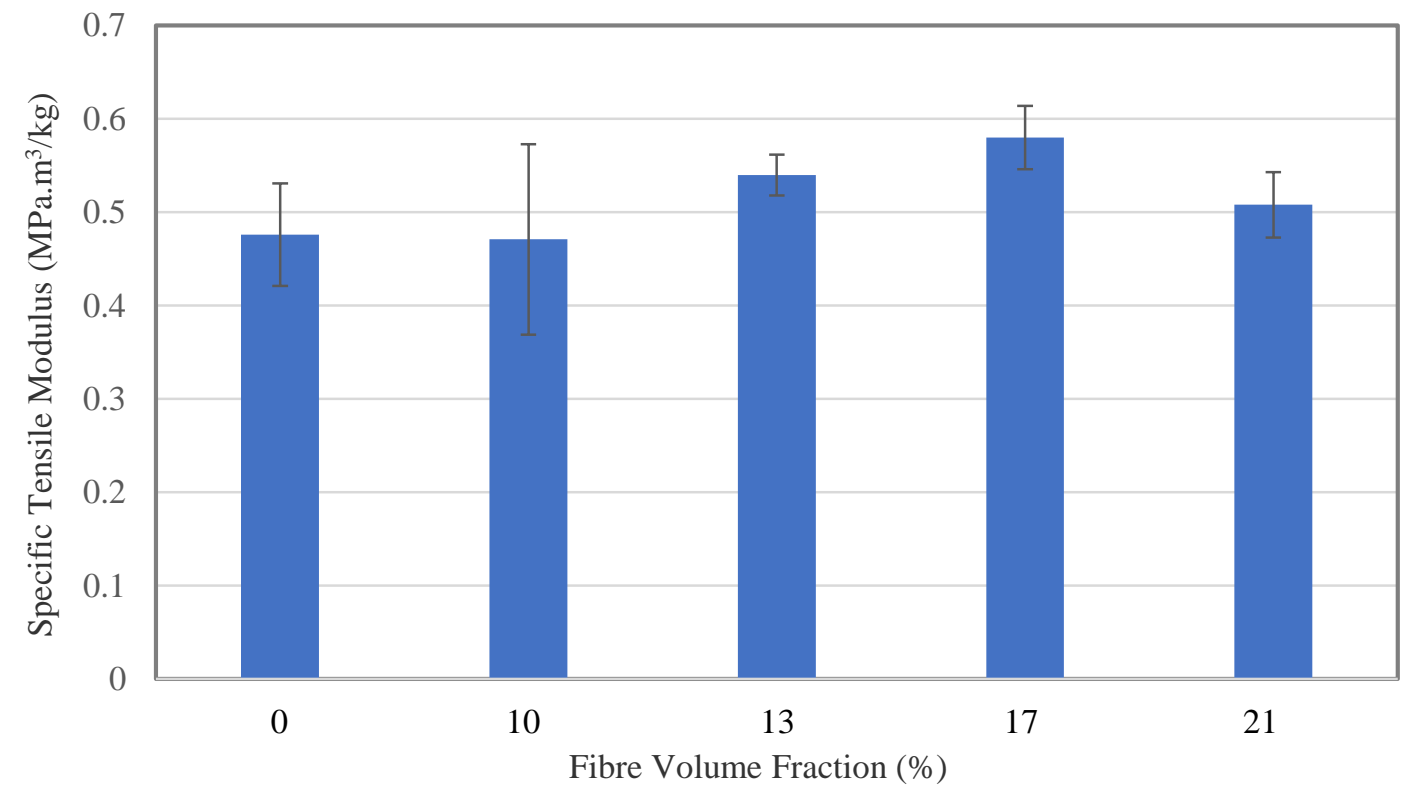

Figure 2. Average specific tensile strength of AH fibre composites with different volume fraction. 


\subsection{Hardness Test}

Laminates $\mathrm{A}_{2}$ with fibre volume of $13 \%$ has the highest mean $\mathrm{HV}$ hardness $(6.30 \mathrm{HV})$, followed by $\mathrm{A}_{3}(6.21 \mathrm{HV}), \mathrm{A}_{1}(6.14 \mathrm{HV}), \mathrm{A}_{0}(6.06 \mathrm{HV})$ and then $\mathrm{A}_{4}(5.97 \mathrm{HV})$. The addition of fibre in polymer composite has increased the hardness of laminate composites, to a certain extent. However, Laminate $\mathrm{A}_{4}$ have the lowest hardness value and are lower than neat HDPE laminates. This may due to the present of weak fibre-polymer interface, where such presence may adversely affect the mechanical performance and lifespan of the composites. The voids also allow moisture to penetrate the composite, which would accelerate the degradation of fibre composites. Figure 3 shows the mean hardness (HV) of AH fibre composites.

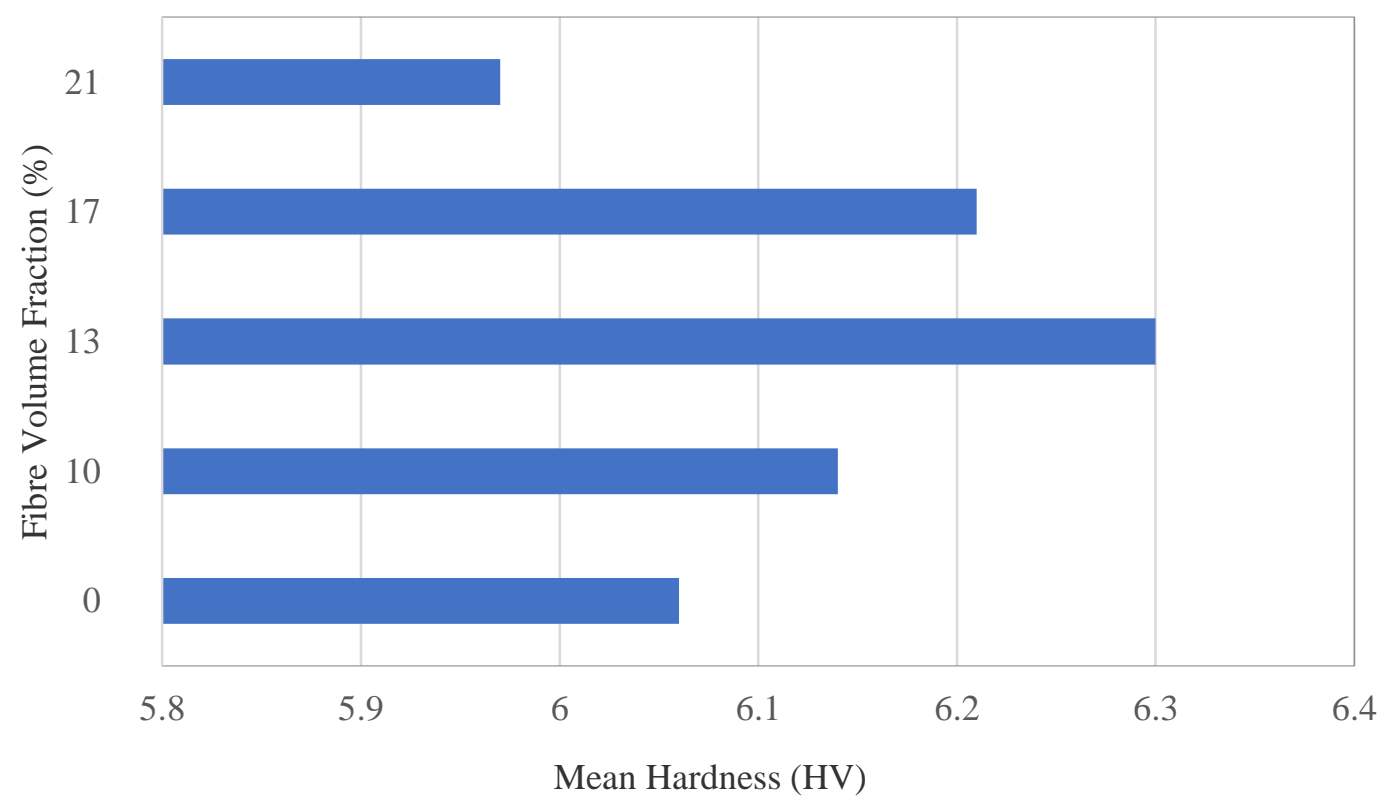

Figure 3. Mean hardness (HV) of jackfruit fibre composites.

\subsection{SEM Analysis}

It is observed that $\mathrm{A}_{4}$ specimens have more voids or gaps within the laminate compared to $\mathrm{A}_{1}$ specimens. $\mathrm{A}_{4}$ specimen also has more dispersed fibres and is thick, which would cause delamination. This is because the hydrophilic nature of natural fibres and polymer matrix being hydrophobic results in a heterogeneous system. Such characteristic leads to poor adhesion between fibre and matrix, which will ultimately cause debonding between the two[5] (Parida, Dash, \& Das, 2015). This explain the lower tensile strength of $\mathrm{A}_{4}$ laminates. Figure 4 shows the SEM Image of $10 \%$ (left) and $21 \%$ (right) fibre volume fraction AH fibre composites under magnification of $\times 150$. 

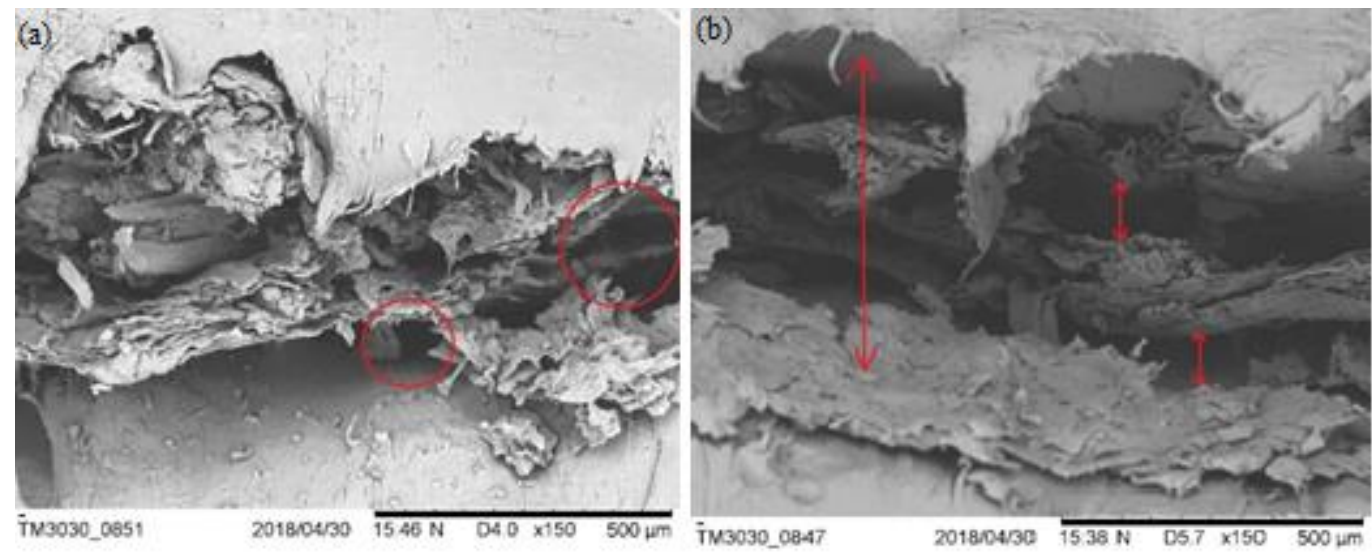

Figure 4. SEM image of (a) $10 \%$ and (b) $21 \%$ fibre volume fraction AH fibre composites under magnification of $\times 150$

\section{Conclusion}

In the tensile behaviour test, composite with $17 \%$ fibre volume fraction exhibit the highest tensile strength and specific tensile strength. The composites with $10 \% v_{\mathrm{f}}$ and $13 \% v_{\mathrm{f}}$ has slightly better tensile properties than the HDPE laminate. For Artocarpus heterophyllus fibre reinforced HDPE composite, the tensile strength increases as the fibre content increases to an optimum level. The fibre composite also have lower density and better tensile properties than neat HDPE. $\mathrm{A}_{2}$ laminate with $13 \%$ fibre volume fraction have the highest hardness value (HV) of $6.30 \mathrm{HV}$. Other composites perform better than neat HDPE in hardness test, except for A4 laminate which have $21 \%$ fibre volume fraction. The SEM analysis shows the bonding of fibre-fibre and fibre-matrix in $10 \% v_{\mathrm{f}}$ composite are better than in $21 \% v_{\mathrm{f}}$ composite. The presence of voids is also more significant in $21 \% v_{\mathrm{f}}$ composite

\section{Acknowledgements}

The authors express gratitude to Universiti Malaysia Sarawak for providing the opportunity and supports to conduct this research.

\section{References}

[1] Ku, H., Wang, H., Pattarachaiyakoop, N., and Trada, M. (2011). A Review on The Tensile Properties of Natural Fiber Reinforced Polymer Composites, Composites Part B: Engineering, Vol. 42, No. 4, 856-873.

[2] National Solid Waste Management Department Ministry of Housing and Local Government Malaysia. (2011). A Study on Plastic Management in Peninsular Malaysia. Selangor: Golden Ecosystem Sdn. Bhd.

[3] Malaysia Department of Agriculture Putrajaya. (2016). Fruit Crops statistics. Kuala Lumpur: Jabatan Percetakan Negara.

[4] Cao, Y., Sakamoto, S. and Goda, K. (2007). Effects of Heat and Alkali Treatments on Mechanical Properties of Kenaf Fibers. In 16th International Conference on Composite Materials, 8-13.

[5] Parida, C., Dash, S. K. and Das, S. C. (2015). Effect of Fiber Treatment and Fiber Loading on Mechanical Properties of Luffa -Resorcinol Composites. Indian Journal of Materials Science, 1-6. 